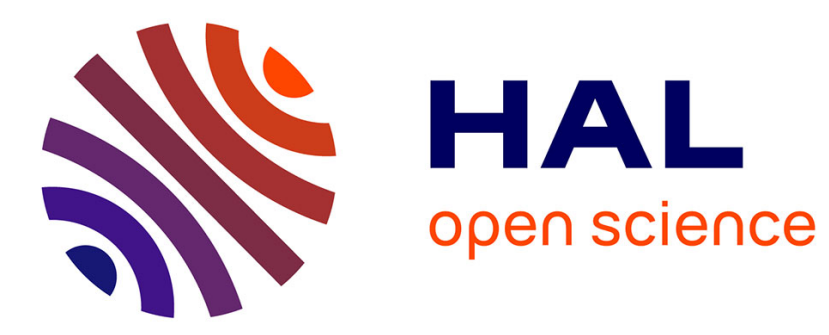

\title{
Selecting the cases that defined Europe: complementary metrics for a network analysis
}

Fabien Tarissan, Yannis Panagis, Urska Sadl

\section{To cite this version:}

Fabien Tarissan, Yannis Panagis, Urska Sadl. Selecting the cases that defined Europe: complementary metrics for a network analysis. IEEE/ACM International Conference on Advances in Social Networks Analysis and Mining, Aug 2016, San Francisco, United States. hal-01366475

\section{HAL Id: hal-01366475 \\ https://hal.science/hal-01366475}

Submitted on 14 Sep 2016

HAL is a multi-disciplinary open access archive for the deposit and dissemination of scientific research documents, whether they are published or not. The documents may come from teaching and research institutions in France or abroad, or from public or private research centers.
L'archive ouverte pluridisciplinaire HAL, est destinée au dépôt et à la diffusion de documents scientifiques de niveau recherche, publiés ou non, émanant des établissements d'enseignement et de recherche français ou étrangers, des laboratoires publics ou privés. 


\section{Selecting the cases that defined Europe: complementary metrics for a network analysis}

\author{
Fabien Tarissan \\ Université Paris-Saclay, ISP, ENS Cachan, CNRS, \\ Cachan, France \\ Email: fabien.tarissan@ens-cachan.fr
}

\author{
Yannis Panagis and Urška Šadl \\ iCourts Centre of Excellence for International Courts \\ Faculty of Law, Copenhagen, Denmark \\ Email: ioannis.panagis@jur.ku.dk \\ urska.sadl@jur.ku.dk
}

\begin{abstract}
Do case citations reflect the "real" importance of individual judgments for the legal system concerned? This question has long been puzzling empirical legal scholars. Existing research typically studies case citation networks as a whole applying traditional network metrics stemming from graph theory. Those approaches are able to detect globally important cases, but since they do not take time explicitly into account, they cannot provide a comprehensive account of the dynamics behind the network structure and its evolution.

In this paper we provide such a description, using two node importance metrics that take time into account to study important cases in the Court of Justice of the European Union over time. We then compare cases deemed as important by the metrics, with a set of 50 cases selected by the Court as the most important (landmark) cases.

Our contribution is twofold. First, with regard to network science, we show that structural and time-related properties are complementary, and necessary to obtain a complete and nuanced picture of the citation network. Second, with regard to the case law of the Court, this study provides empirical evidence clarifying the motivation of the Court when selecting the landmark cases, revealing the importance of symbolic and historical cases in the selection. In addition, the temporal analysis sheds new light on the network properties specific to the landmark cases that distinguishes them from the rest of the cases. We validate our results by providing legal interpretations that sustain the highlights provided by the proposed network analysis.
\end{abstract}

Index Terms-Citation networks, Directed acyclic graphs, Relative in-degree, Average longevity, Authority scores, European Court of Justice

\section{INTRODUCTION}

The Court of Justice of the European Union (the Court) is often considered as the most powerful international court in the world [1]. Legal scholars have often emphasized its key role in the European integration process, typically relying on a handful of landmark judgements in which the Court defined the European legal order citealec.

When the Court in 2004 at a point of the biggest enlargement of the European Union from 15 to 25 members selected its "50 signature cases" for the newcomers, its selection closely matched the scholarly selection. These cases are considered as

This research is partly funded by the Danish National Research Foundation Grant no. DNRF105 and conducted under the auspices of iCourts, the Danish National Research Foundations Centre of Excellence for International Court important pre accession case law ${ }^{1}$ (also referred to as landmark cases) and are publicly accessible on the Court's website. By contrast, the selection criteria are not accessible to the general public. Internal documents of the Court, however, indicate that the main criteria were first, whether the judgements were unanimously recognized as leading cases, structuring the legal order of the Community, and second, generally considered as important references in the area. So far, the relevance of those criteria was not examined empirically because it was simply assumed that these judgements were the landmark judgements with continuous relevance for European law.

The purpose of this paper is precisely to investigate this question by relying on the graph of citations extracted from the judgements. Indeed, as many real-world networks, the structure of case law networks can be analysed using graphs, where nodes stand for the judgements and links depict the connections between them, that is, the references to previous judgements. This induces a directed acyclic graph (DAG) on which one can rely to detect important legal decisions. Although recent, this approach has attracted considerable attention and has been applied to a series of jurisdictions [2][13].

In this context, the fact that judgements rely on former ones to motivate their decisions led the community to focus in particular to degree-related properties. The intuition is that an important judgement should be widely referred to, thus leading to a greater degree than other judgements. In this regard, the oft-used authority score, initially proposed by Kleinberg in the context of web searching [14], has been widely used to identify the landmark decisions and gain a general overview of the structure of the case law of individual courts. To further refine the analysis and develop dedicated metrics accounting for the moment at which the judgements are issued (that is, at the time when the cases are decided) Tarissan and NollezGoldbach in a more recent study [13], [15] proposed to rely on the temporal properties induced by the DAG structure. The study showed that this approach provides an alternative point of view of what is considered as an important decision through time and what can be labeled as rising star decisions that might become important reference points in the future.

\footnotetext{
${ }^{1}$ These were cases, which the acceding Member States had to translate into their respective official languages. See http://curia.europa.eu/jcms/jcms/Jo2 14955/
} 
Following these promising results, this paper investigates whether the selection of landmark cases by the Court matches an objective selection that relies on citation-based properties, using network analysis. In addition, we assess for the first time the relevance of the authority score compared to timerelated properties. Rather than confronting the two notions, the analysis reveals first, that the points of view provided are complementary and second, that by combining them it is possible to produce a more precise picture of the evolution of the importance of individual cases over time. This further provides a deeper and more nuanced insight into how international courts develop international law and the role that the landmark cases play in this process.

The remainder of the paper is organised as follows. First we present the existing work related to network analyses in the context of law (Section II) before providing the background necessary for the study (Section III). Then we turn to the network analysis, relying first on a static point of view (Section IV) before investigating how the evolution of the importance of the cases over time impact the analysis (Section V). Finally, we conclude the paper by laying the foundations for future research (Section VI).

\section{RELATED WORK}

Several previous studies combined law and computer science, to either model legal reasoning or to extract information from legal databases. Most recently, a new line of research has emerged, which considers legal decisions as complex networks [2]. This originated from studies that analysed the evolution of the jurisprudence of the American Supreme Court through direct references (citations) between judgements [3][6]. The approach has then been applied to various national settings, ranging from the Canadian [7] to the Italian [8], the Dutch [9], and the French [10], [11] legal systems.

With regard to international courts, Derlen et al., and Mirshavalad et al., [12], [16], [17] applied network analysis to the case law of the Court of Justice, presenting the application of PageRank [18] and community detection techniques [17] to get an overview of the structure of the Court's network. The same authors in [12] examined the structural properties of the case law and the legislative network of the European Union without quantifying the importance of individual nodes-cases. Lupu and Voeten [19] studied the case law of the European Court of Human Rights using hubs and authorities as proxies for statistical analysis of the case law properties. Tarissan and Nollez-Goldbach [13], [15] conducted research on the International Criminal Court, and Pelc [20] on the Appellate Body of the World Trade Organisation. Puig provided another interesting application of network analysis to international dispute resolution (without, however, considering individual decisions) [21], focusing on arbitrator patterns and importance of individual arbiters in the field of international arbitration.

To the best of our knowledge, this study is the first that a) provides a temporal perspective in the analysis of the case law of the European Court of Justice and b) combines structural

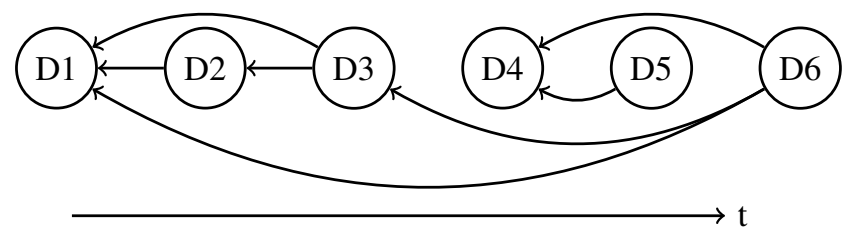

Fig. 1. Example of a DAG depicting citations processes

(in-degree, authority scores) and time related (relative indegree, average longevity) properties.

\section{DATASET AND METHODOLOGY}

\section{A. Network analysis}

It is common to represent a citation network as a directed graph $G=(V, E)$. In our context, a node $v \in V$ represents the judgement in a case - identified by its CELEX number ${ }^{2}-$ and a link $(u, v) \in E$ between two nodes $u$ and $v$ exists if the case $u$ cites the case $v$. Although this representation does not directly account for temporal properties, temporal aspects are encoded in this formalism since time induces a natural acyclic property; a judgement cannot refer to a future judgement.

Depicting a citation network as a directed graph enables the analysis of its structure. To this purpose, the standard approach consists entails relying on the number of times a node is cited by another one. More formally, if $v \in V$ is a node, we denote by $C_{i n}(v)=\{u \in V \mid(u, v) \in E\}$ the set of decisions that cite $v$ and we call $\operatorname{deg}_{i n}(v)=\left|C_{i n}(v)\right|$ the in-degree of $v$. Intuitively a high in-degree indicates that a decision is used to ground many future decisions thus quantifying its importance. In the context of judicial networks, a variant of this notion is also referred to as the authority score [4], [9] introduced by Kleinberg [14] in the context of web searching.

However, the acyclic property led to the criticism of degreerelated properties for being strongly biased towards old nodes that have obviously more opportunities to get cited. In the example of Fig. 1 for instance, although D1 attracts more citations than D4 (leading to the interpretation that D1 is more important than D4), one could argue that D4 is actually more important as it has attracted all possible citations it could get from the subsequent cases.

To overcome this issue, Tarissan and Nollez-Goldbach [15] proposed to put this absolute value into perspective by dividing the number of citations by the number of citations that a node could have possibly had. Formally, let $\operatorname{date}(v)$ the date at which $v \in V$ is issued and Future $(v)=\{u \in V \mid$ date $(u)>$ date $(v)\}$ the set of decisions issued after $v$, one defines the relative in-degree of $v$ as:

$$
\operatorname{deg}_{i n}^{r e l}(v)=\frac{\operatorname{deg}_{i n}(v)}{|\operatorname{Future}(v)|}
$$

The authors of [15] also highlighted that another aspect might help identify important decisions. Indeed, several stud-

\footnotetext{
${ }^{2} \mathrm{http} / / /$ eur-lex.europa.eu/content/help/faq/celex-number.html
} 
ies [4], [5] highlighted the fact that, while most decisions cease to be cited after a while (they depreciate), landmark decisions depreciate at a slower rate (they tend to be cited for a longer period). Relying on this observation, they proposed to use the time between the date of two related decisions as an indicator of the importance of the decision being cited.

More formally, if we define the temporal distance of a link $(u, v) \in E$ as the value $\operatorname{td}(u, v)=\mathrm{d}(u)-\mathrm{d}(v)$, then one can define the average longevity $\lg (v)$ of $v$ as the average temporal distance over all links towards $v$ :

$$
\lg (v)=\frac{\sum_{u \in C_{i n}(v)} \operatorname{td}(u, v)}{\operatorname{deg}_{i n}(v)}
$$

The intuition is that a high average longevity of a decision means that this decision is being used to ground future decisions as time passes, thus indicating that it is a good candidate for a landmark decision.

\section{B. European Court of Justice}

In this study we use the case law of the Court of Justice, which is publicly available. The Court is the main judicial institution in the European Union, whose task is to ensure that in the interpretation and the application of the European Treaties, the law is observed (Article 19). The Court is composed of 28 judges, one from each Member State, and 11 Advocates General, who assist it. It decides approximately 600 cases per calendar year.

The dataset we used consists of 5599 judgements and Court Opinions from the Court of Justice of the European Union, issued from 1954 until March, $17^{\text {th }}$ 2002, day when the 50 landmark cases were released. All case law is available at EUR-Lex, the official portal of European Union $\mathrm{law}^{3}$. By taking into account the citation information published by EURLex, we built the corresponding case-to-case citation network, which in turn consists of all the aforementioned cases as nodes and 13609 edges-case citations. In addition, we extracted the following information:

1) The 50 landmark decisions: Internal documents of the Court suggest that the Research and Documentation department prepared the list of 50 cases of the Court and the General Court after consultations with the presidents of both courts, and that the selections were approved by the Presidents of the Courts ${ }^{4}$. To be included in the selection the judgments had to be unanimously recognized as leading cases, structuring the legal order of the Community, and generally considered as important references in the area. Note that the frequency of citations in subsequent judgements was not the only factor ${ }^{5}$.

Also, the Court provided two lists, distinguishing cases before 2001 from cases after 2001. In this study, we focus exclusively on the former, which contains the best known cases in European law.

\footnotetext{
${ }^{3} \mathrm{http}: / /$ eur-lex.europa.eu

${ }^{4}$ Internal Memorandum of the Court (Sep. 17, 2003), see [22]

${ }^{5}$ Internal Memorandum of the Court (May 17, 2002), see [22]
}

2) Classification of the Court: When the Court decides a case, the Research and Documentation Directorate - supervised by reporting judges in individual cases - assigns it one or more classifications, depending on the legal questions considered in the case ${ }^{6}$. The objective is to facilitate the work of the Court as well as research. The classifications are fed into several databases, including EURLEX, the main online gateway to EU legislation and case law ${ }^{7}$. They are available on the official website, where they are stored as bibliographical information under the category subject matter (that is as metadata). The metadata contains several subject matters and we use the primary classification that designates the content of the case most generally, to avoid too many subgroups. We correct for that classification if the subsequent keywords assigned to the case provide a closer description of the content of the case (that is, when they all fall under the second most general classification, indicating that the primary classification might not be the most general or misguided).

3) Additional classification: As an alternative to the Court's classification, we systemmatized the landmark cases on the basis of close reading, and existing literature, which investigated the different aspects of landmark decisions [23], [24]. In particular, the cases are systematized on the basis of their intrinsic properties, such as: (1) their practical and symbolic importance. For instance, according to this criterion cases like that the literature considers as "fundamental" will be classified as cases with mainly symbolic importance (referred to further as symbolic), while other, which are discussed for their relevance for solving concrete problems, will be classified as cases that had primarily practical importance (practical); (2) the Courts law-making initiative (establishment of new judge-made principles vs. interpretation of Treaty Articles). This category divides historic cases in two subcategories, distinguishing between outcomes that were not strictly based on the Treaty Articles (judge made), and cases, which were grounded in the interpretation of concrete Treaty Articles (treaty); (3) juridical consequences and effects (did the Court limit or mitigate the consequences of its rulings in practice (yes) or not (no)); (4) according to their age (old, decided between 1954 and 1979 vs. new, decided between 1980 and 2001); and (5) the subject of protection, which can be the individual (referred to further as category A), the authority of the legal order (category B), the functioning of the internal market (category C), and the general principles of EU law (category D).

\section{The network under study}

To juxtapose the vision of the Court to the objective measures of case importance on the basis of network analysis, we applied the following process: from the dataset, we extracted all the citations from all cases until March $17^{\text {th }}, 2002$,

\footnotetext{
${ }^{6}$ For more detailed information on the role of the Research and Documentation Directorate, see Research and Documentation Directorate, CURIA, http://curia.europa.eu/jcms/jcms/Jo2_11968/ direction-de-la-recherche-et-documentation (last accessed Mar. 11, 2016).

${ }^{7}$ EUR-LEX, http://eur-lex.europa.eu/homepage.html (last visited Mar. 11, 2016)
} 
constructed the network of citations to precedent, computed on it the different metrics described in Section III-A, and filtered out all cases decided after 2001 in order to simulate the fact that those cases were not taken into account in the selection of the 50 landmark cases.

\section{STATIC ANALYSiS}

In this section, we investigate whether the selection made by the Court of Justice of the European Union when selecting the 50 landmark cases in 2002 matched the point of view provided by the network analysis of the citation process. To do so, we compare the list of the 50 landmark cases of the Court to the list of the 50 most important cases according to network analysis, with respect to the different metrics presented in Section III-B. The rationale is the following: if the criterion for selecting the 50 cases is objectively the importance of the judgements measured by its ability to serve as a grounding base for many future decisions, then this should be reflected in the analysis of its citation patterns.

We start by conducting the analysis on the complete network (Section IV-A) before focusing on the classification provided by the Court (Section IV-B).

\section{A. Categories}

Table I presents the results obtained by taking into account all the cases. Absolute values in Table 1 stand for the number of common cases $^{8}$ between the list made by the Court and the one identified by network analysis (row entitled Total in the table). In order to better understand the impact of each metric, we also provide the distribution of the common cases according to the additional classification presented in Section III-B3. The percentage stands for the proportion of common cases in each category. For example, if we look at the category "Age", $41 \%$ of the top 50 cases based on the indegree that are common with the 50 landmark cases, belong to the category "old" whereas the rest $59 \%$ to the category "new".

Table I shows that network analysis and the Court's selection match poorly. The most efficient property in this regard is the simple in-degree but it only succeeds in detecting 17 landmark cases (33\%). In addition, if we use all four properties, we only increase this amount to 23 (46\%). Obviously, the Court does not solely rely on the objective importance of cases, which confirms the relevance of the question of hidden criteria made by the Court to pick out those cases.

With regard to the different aspects highlighted by the computed metrics, one can see that, as underlined in Section III-A, relative in-degree and average longevity provide a contrasting view. Relative in-degree focuses on recent cases $(80 \%$ of detected landmarks are recent) while average longevity focuses on old cases (100\% of detected landmarks are old). This last argument is strengthened by the fact that old cases are not numerous in the selection of the Court. Similarly, one can observe that in-degree is biased towards old cases, retrieving

\footnotetext{
${ }^{8}$ this is equivalent to the recall used in Information Retrieval contexts.
}

$53 \%$ of old landmark cases, while detecting only $30 \%$ of the new ones.

From a legal perspective, the results obtained on the classification used in this study are compelling. If one focuses for instance on the importance of the landmark cases, it is remarkable that most network metrics (if not all) capture landmark cases that have or had a practical importance (they solved concrete legal issues), leaving the cases that had a more symbolic character (they did not solve concrete problems but defined the nature of the legal system and its fundamental features) undetected (although this is alleviated by the fact that practical cases make up more than $80 \%$ of listed cases). This is an interesting finding since it provides empirical evidence that the motivation of the Court when selecting the landmark cases was to take into account cases that are not widely used and cited but important on a more general or principled level.

\section{B. Classification of the Court}

One limitation of the analysis presented above is that it aggregates all information contained in the dataset and puts at the same level all topics addressed by the Court. In order to provide a more nuanced picture of which cases are important according to their main subject matter as explained in Section III-B2, we extracted the sub-networks according to the classification provided by the Court ${ }^{9}$ and conducted a similar study as above. Note that this process has a strong impact on the structure of the networks since each sub-network now only contains links between its nodes, thus discarding citations between cases related to different topics.

Results are presented in Table II. Each category is given with the number of $n$ landmark cases selected by the Court (1st column). The remaining columns indicate the number of common cases in the $n$ most important cases with respect to the different metrics. For instance, since the topic "Institutions" contains 6 landmark cases listed by the Court, we computed how many of those 6 cases are present in the 6 most important cases according to network analysis ( 3 for in-degree, authority and relative in-degree, only 2 for average longevity).

Table II presents interesting outcomes. First, it shows that taking the legal context of a case into account before quantifying its importance impacts the results. In that regard, it is remarkable that landmark cases related to the "Free movement of goods" and "Institutions" are well captured by all different metrics. Almost $50 \%$ of related landmark cases listed by the Court are indeed identified as important by the network analysis.

By contrast, it is surprising that landmark cases related to other fields, such as "Competition" for instance, are not listed as the most important decisions within their categories. This of course depends to a large extent on small the size of the category, in the 50 cases' sample. The categories "Brussels Convention", "External relations" and "Taxation" are not captured by the metrics but they are also poorly

\footnotetext{
${ }^{9}$ Due to space limitation and the focus of our study, we limited the analysis to subject matters (classifications of the Court) that contain at least one landmark case.
} 


\begin{tabular}{|ll|c|c|c|c|}
\hline \multicolumn{2}{|c|}{ Category } & In-degree & Authority & Rel. in-degree & Longevity \\
\hline & Total & $\mathbf{1 7}$ & $\mathbf{8}$ & $\mathbf{1 0}$ & $\mathbf{7}$ \\
\hline \multirow{2}{*}{ Age } & old (13) & $7(41 \%)$ & $4(50 \%)$ & $2(20 \%)$ & $\mathbf{7}(\mathbf{1 0 0} \%)$ \\
& new (37) & $10(59 \%)$ & $4(50 \%)$ & $\mathbf{8}(\mathbf{8 0 \%})$ & $0(0 \%)$ \\
\hline \multirow{2}{*}{ Importance } & practical (41) & $\mathbf{1 5}(\mathbf{8 8 \%})$ & $\mathbf{8}(\mathbf{1 0 0} \%)$ & $\mathbf{1 0}(\mathbf{1 0 0} \%)$ & $4(57 \%)$ \\
& symbolic (9) & $2(12 \%)$ & $0(0 \%)$ & $0(0 \%)$ & $3(43 \%)$ \\
\hline \multirow{2}{*}{ Mitigate } & no (30) & $9(53 \%)$ & $2(25 \%)$ & $6(60 \%)$ & $5(71 \%)$ \\
& yes (20) & $8(47 \%)$ & $6(75 \%)$ & $4(40 \%)$ & $2(29 \%)$ \\
\hline \multirow{2}{*}{ Interpretation } & judge made (20) & $6(35 \%)$ & $4(50 \%)$ & $6(60 \%)$ & $3(43 \%)$ \\
& treaty (30) & $11(65 \%)$ & $4(50 \%)$ & $4(40 \%)$ & $4(57 \%)$ \\
\hline \multirow{4}{*}{ Protection } & A (16) & $\mathbf{7 ( 4 1 \% )}$ & $2(25 \%)$ & $3(30 \%)$ & $\mathbf{3}(\mathbf{4 3 \%})$ \\
& B (11) & $4(24 \%)$ & $1(12 \%)$ & $0(0 \%)$ & $2(29 \%)$ \\
& C (15) & $4(24 \%)$ & $\mathbf{4 ( 5 0 \% )}$ & $\mathbf{6}(\mathbf{6 0 \%})$ & $2(29 \%)$ \\
& D (8) & $2(12 \%)$ & $1(12 \%)$ & $1(10 \%)$ & $0(0 \%)$ \\
\hline
\end{tabular}

TABLE I

NUMBER OF LANDMARK CASES IN THE LIST OF THE 50 MOST IMPORTANT CASES ACCORDING TO THE NETWORK ANALYSIS.

\begin{tabular}{|lc|c|c|c|c|}
\hline Thematic & & In-degree & Authority & Rel. in-degree & Longevity \\
\hline Agriculture & 5 & 0 & 0 & 0 & 0 \\
\hline Approximation of laws & 3 & 1 & 1 & 1 & 0 \\
\hline Brussels Convention & 1 & 0 & 0 & 0 & 0 \\
\hline Competition & 6 & 0 & 0 & 1 & 1 \\
\hline External relations & 2 & 0 & 0 & 0 & 0 \\
\hline Freedom of establishment & 4 & 0 & 0 & 1 & 0 \\
\hline Free movement of goods & 10 & $\mathbf{4}$ & $\mathbf{4}$ & $\mathbf{3}$ & $\mathbf{3}$ \\
\hline Free movement of persons & 4 & 0 & 0 & 1 & 0 \\
\hline Institutions & 6 & $\mathbf{3}$ & $\mathbf{3}$ & $\mathbf{3}$ & $\mathbf{2}$ \\
\hline Social Policy & 5 & 1 & 1 & 1 & 1 \\
\hline Taxation & 1 & 0 & 0 & 0 & 0 \\
\hline \hline Total & $\mathbf{5 0}$ & $\mathbf{1 0}$ & $\mathbf{9}$ & $\mathbf{1 1}$ & $\mathbf{7}$ \\
\hline
\end{tabular}

TABLE II

NUMBER OF LANDMARK CASES IN THE LIST OF THE MOST IMPORTANT CASES ACCORDING TO THE NETWORK ANALYSIS AND THE SUBJECT MATTER.

represented in the selection of landmark cases, thus leading to inconclusive results.

In order to have a better view of what impact the legal context has on the analysis, we also computed the ranks of individual cases in the complete network and compared them to the rank in their corresponding sub-networks. Results are presented in Table III below. The results presented in this table contrast with the ones of Table II. When focusing in particular on the 10 most important cases, it is clear that the analysis greatly benefited from the adjustment of the computations to include their most relevant legal context. Such additional information increased the importance of the cases with respect to their subject matter.

\section{EVOLUTION OF THE IMPORTANCE}

The analysis conducted in Section IV enables us to objectively quantify the importance of landmark cases, in particular those selected by the Court. The analysis nonetheless points to another conclusion: namely, when selecting landmark cases, the Court tried to provide a historical perspective of what was considered important. Translated into the network approach conducted in this paper, this means that the coefficients capturing the importance of a case might have been high at some point in the past but were low in 2002. In this case the importance of the case will remain undetected by the static analysis performed so far.

In order to assess this claim, we conducted a temporal analysis by studying how the different metrics evolved over time. We mimicked the growth of the network and computed the values of the coefficients at each time step and for each case. It should be pointed out that for the in-degree and the longevity, the value of the coefficient can only grow by definition of the metrics. This is not the case for the authority score and the relative in-degree, which is why we exclusively focus on those two properties in the remaining of the paper.

This perspective allows us to investigate two questions that we address in the remaining of the section: is there any specific profile in the evolution of the properties for landmark cases that distinguish them from regular cases (Section V-A)? Does this historical perspective provide an explanation for the presence of landmark cases undetected in the previous analysis (Section V-B)?

\section{A. Profile of the landmark cases}

The first question we address is whether the landmark cases have a particular profile that distinguishes them from regular (non-landmark) cases. In particular, how and when do they gain authority in the networks?

Figure 2 presents the evolution of the importance of the landmark cases according to their authority scores (left) and relative in-degree (right) and compares it to the regular cases. It shows that for the two properties, landmark cases have a profile which clearly differs from the profile of regular cases. Focusing on the relative in-degree for instance, all cases experience a slow but steady decline of the value. This is expected since, as new cases are decided, it becomes 


\begin{tabular}{|c|c|c|c|c|c|c|c|c|c|c|c|c|}
\hline \multirow{2}{*}{ Network } & \multicolumn{3}{|c|}{ In-degree } & \multicolumn{3}{|c|}{ Authority } & \multicolumn{3}{|c|}{ Rel. in-degree } & \multicolumn{3}{|c|}{ Longevity } \\
\hline & top 5 & top 10 & top 50 & top 5 & top 10 & top 50 & top 5 & top 10 & top 50 & top 5 & top 10 & top 50 \\
\hline Complete & 4 & 5 & 17 & 1 & 1 & 8 & 1 & 1 & 10 & 1 & 3 & 7 \\
\hline Sub-network & 11 & 14 & 26 & 8 & 10 & 19 & 10 & 12 & 26 & 5 & 14 & 20 \\
\hline Ratio & 2.75 & 2.8 & 1.5 & 8 & 10 & 2.4 & 10 & 12 & 2.6 & 5 & 4.67 & 2.9 \\
\hline
\end{tabular}

TABLE III

NUMBER OF LANDMARK CASES IN LIST OF THE 5, 10 AND 50 MOST IMPORTANT CASES ACCORDING TO THE NETWORK ANALYSIS.
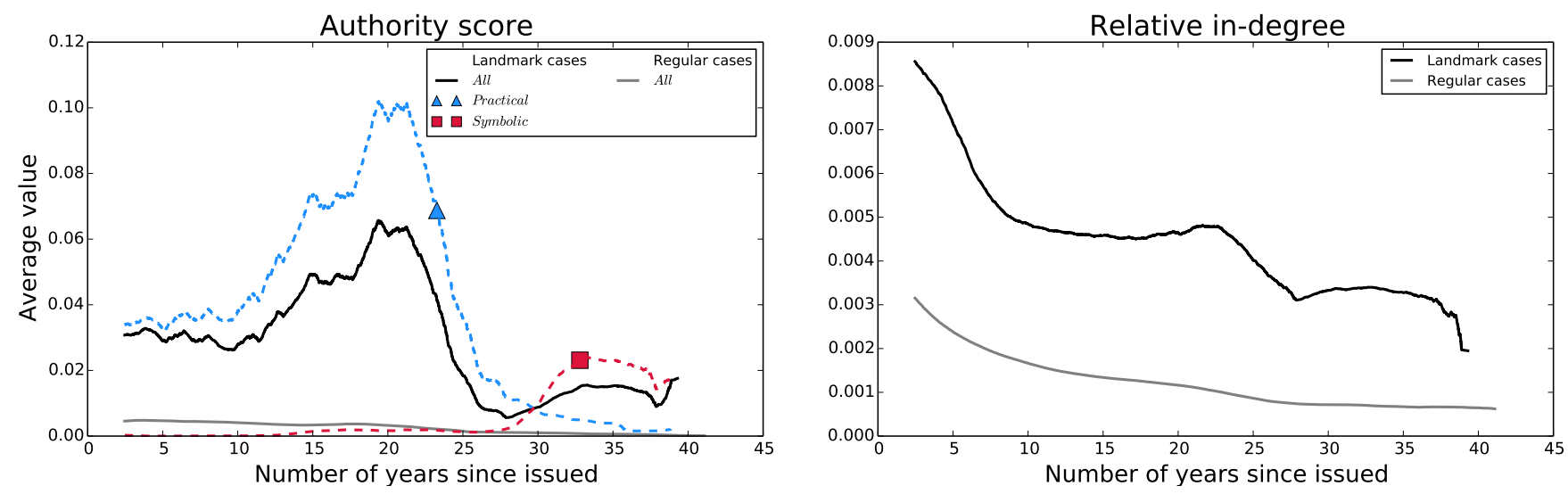

Fig. 2. Landmark vs. regular cases

more difficult for a case to maintain the ratio computed by the metric. However, one can see that the relative in-degree is always significantly higher than the relative in-degree of regular cases.

Regarding the authority score, one can also notice a clear distinction between landmark cases (straight black line) and regular cases (grey line) ${ }^{10}$. More importantly, there seems to be a maturation process spanning several years before the landmark cases obtain their maximal value. Then one can observe a sharp decline of the authority and finally a clear regain of importance at the end, leading to the impression that landmark cases might have a different maturation process.

Investigating this question in detail, we used the additional classification presented in Section III-B3 to study whether any specific properties of the landmark cases might explain this evolution. It resulted that, as shown on the left part of Figure 2, symbolic cases (dashed line marked with a triangle) and practical cases (dashed line marked with a square) have very different profiles. Symbolic cases tend indeed to have a very long maturation process, leading such cases to have very low authority according to the network analysis (even lower than average regular cases) before gaining their fame long time after being issued (30 years in average). This is in sharp contrast with the profile of practical cases that start loosing their authority after 20 years.

These findings confirm the theory of incremental decision making of courts [25], according to which courts postpone the full effect of decisions that introduce legally of politically contentious principles in order to preserve their authority and

\footnotetext{
${ }^{10}$ the result is the same in average if we take a random selection of 50 regular cases instead of all regular cases.
}

legitimacy.

\section{B. Remembrance of the past}

The conclusions drawn from the study of the evolution of the authority of the cases question the relevance of assessing the importance of a case at a specific time. When dealing with a specific topic in particular, it is very likely that important cases are taking the lead against formerly important cases related to the same issue. In fact, this is how the law evolves.

To illustrate this point, we focus in the following on the landmark cases that concern the "Free movement of goods" (as subject matter). This category is interesting in this context for two reasons: first, it is the category which contains the most landmark cases (10) listed by the Court, revealing the particular emphasis that the Court placed on this topic, and second, this category is the one where the Court's and the network's points of view match best. Indeed, almost half of the cases were considered important by all applied metrics (see Table II), begging the question why other landmark cases were not considered important.

Figure 3 presents the evolution of the authority score (left) and the relative in-degree (right) as a function of time for the landmark decisions related to the "Free movement of goods". This plot is related to the static analysis of Section IV as the values at the very end of the plot are the ones used to rank the cases. Focusing in particular on the authority scores, one can see that Dassonville (61974CJ0008) is the most important one, followed by Cassis de Dijon (61978CJ0120), then Keck and Mithouard (61991CJ0267), Comm v GE (Beer purity) (61984CJ0178), etc.

Figure 3 provides several interesting observations. First, it clearly strengthens our assumption regarding the forgot- 


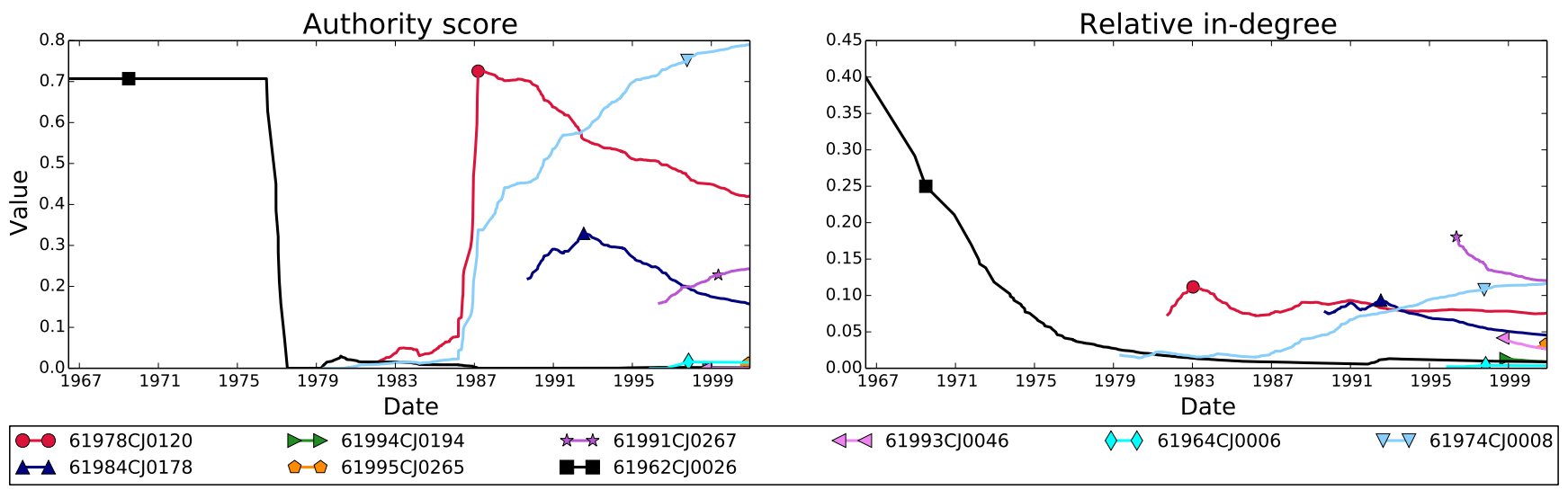

Fig. 3. Free movement of goods

ten cases which were important in the past. Van Gend (61962CJ0026) in particular was one of the less important cases in 2002 and, as such, not identified as an important case by network analysis in Section IV. However, the temporal approach reveals that it has been a key case in the seventies, before it depreciated. At that point, namely, the Dassonville and the Cassis de Dijon cases were decided and took the lead in legal development. This shows that adding a temporal perspective to a more structural network analysis is essential in order to obtain a comprehensive picture of case importance.

Second, the comparison between the evolution of authority scores and relative in-degree shows that while authority scores can detect such shifts between leading cases in a particular context, relative in-degree provides a more precise vision of the evolution of importance. Focusing on Cassis de Dijon for instance, the evolution of its authority score seems to indicate a sharp increase of importance (along with Dassoville, although even sharper) before a clear decline. This perspective is contrasted with the evolution of its relative in-degree showing a steady importance over time.

As pointed out previously, the natural evolution of relative in-degree is to decrease over time since the value is a ratio whose denominator grows as the network grows. Thus a prolonged steady value for Cassis de Dijon reveals that, although the authority scores seems to indicate a decline of authority, the case was actively referred to by the judges over an extended period of time when they had to decide cases that concerned the "Free movement of goods" .

In this regard, the evolution of Dassonville is even more spectacular since its value increases over time. Thus not only the case gained authority as suggested by the authority score but it became more frequently cited as time passed. Finally, the relative in-degree also highlights the emerging importance of Keck (61991CJ0267), undetected if using only authority score, that seems to coincide with the two former cases. This analysis thus suggests that the evolution of importance of Dassonville, Cassis de Dijon and Keck is related and should be analysed together in order to obtain a comprehensive understanding of the evolution of this area of law (the free movement of goods).

From a legal perspective, the outcome of the above network analysis matches the legal doctrinal perspective, and further refines it. Namely, in Dassonville, which was decided in 1974, the Court struck down national measures that hindered trade between Member States. It was seen by some commentators as a paradigm shift in EU law, see [24] p. 456). However, the Court did not use the potential that it created for legal development immediately (what we referred to above as incrementalism). Dassonville remained somewhat dormant until Cassis de Dijon was decided in 1979, and revealed its potential (hence the relative in-degree of Dassonville began to increase in the early 1980s, as shown in Figure 3). Cassis the Dijon, by way of comparison, clarified a specific aspect of the case law that Dassonville left open (the mutual recognition principle). Both cases became popular with litigants as they allowed them to fight more and more national measures that protected "domestic" products and trade. This litigation continued until the Court explicitly reversed its permissive Dassonville approach in Keck that immediately applied to all contested measures and trade, in 1993, and, as shown in Figure 3, became an instant landmark. For some time after 1993, the litigants continued to invoke Dassonville to clarify whether any of its aspects were still valid (also reflected in the upward citation trend in Figure 3). These developments are reflected by the complementary network metrics.

In conclusion, the analysis conducted on the "Free movements of goods" illustrates the fact that the perspective provided by the authority score and the relative in-degree are complementary and, combined, can provide a more accurate vision of the evolution of the case law.

\section{CONCLUSIONS}

In this paper we studied the use of structural (in-degree, authority) and time-related (relative in-degree, average longevity) properties in interpreting the structure of citation networks, focusing on the case citation network of the Court of Justice of the European Union. Thereby, we assessed whether the selection of landmark cases from the Court can be justified 
by the application of those metrics. Our results show that a static analysis focusing then only on the latest snapshot of the network can detect nearly half of cases that are considered landmark. This confirms in part the theory that the Court uses other criteria to select important cases. We obtained slightly better results when we dealt with subnetworks, induced by the case topics, where one can observe that for each network the top-10 with respect to a metric, gives a good idea of which are the objectively important cases per area.

The use of the evolving network as a testbed where we incrementally compute authority scores and relative in-degrees, yields compelling results. First of all, it is quite obvious that landmark cases indeed have a very specific profile: The computed metrics for landmark cases are on average a few orders of magnitude higher than those of an average case. Among them, cases of doctrinal importance obtain high authority scores almost 30 years after they were decided. This is in sharp contrast with cases of more practical substance that gain value at least a decade after the were decided, before they depreciate at a point where they are substituted by another practical case.

As regards the comparison of the different metrics used in this paper, we can clearly see that the metrics are complementary, for both the static and the evolutionary network study. Average longevity allows to detect cases that are diachronic on purely legal criteria, whereas relative in-degree spots the rising stars, which is expected as it favours newer judgements. Indegree performs also rather well. It is not surprising that some of the important cases are well cited, however the less cited cases sink according to this metric. It is then the evolution of metrics that unveils the importance of the latter. In the evolutionary study, it becomes clear that authority allows to succession of authoritative case, which is in fact inline with the judicial interpretation of the Court's doctrine. On the other hand, relative in-degree, despite the fact that it favours the more recent cases, shows that cases with authoritative profile, retain their high ranking through the lapse of time, which in turn gives us good candidates for landmark judgments.

All in all, we believe our methodology provides with a useful framework to study the importance of case-law by leveraging the citation network and the available metadata on the case. We seek to extend our methods by defining new metrics or combinations of the existing ones and by extending our study to bi-partite networks, e.g. countries-cases, actorscases, etc.

\section{REFERENCES}

[1] K. J. Alter, The new terrain of international law: Courts, politics, rights. Princeton University Press, 2014.

[2] T. A. Smith, "The Web of Law," San Diego L. Rev., vol. 44, p. 309, 2007.

[3] S. J. Chandler, "The Network Structure of Supreme Court Jurisprudence," The Mathematica Journal, vol. 10, no. 3, pp. 501-526, 2005.

[4] J. H. Fowler and S. Jeon, "The authority of Supreme Court precedent." Social Networks, vol. 30, no. 1, pp. 16-30, 2008.

[5] R. Whalen, "Modeling Annual Supreme Court Influence: The Role of Citation Practices and Judicial Tenure in Determining Precedent Network Growth," in Complex Networks, ser. Studies in Computational Intelligence, R. Menezes, A. Evsukoff, and M. C. González, Eds. Springer Berlin Heidelberg, 2013, vol. 424, pp. 169-176.
[6] J. R. Clough, J. Gollings, T. V. Loach, and T. S. Evans, "Transitive reduction of citation networks," Journal of Complex Networks, vol. 3, no. 2, pp. 189-203, 2015.

[7] T. Neale, "Citation Analysis of Canadian Case Law," Journal of Open Access to Law, vol. 1, no. 1, pp. 1-51, 2013.

[8] T. Agnoloni and U. Pagallo, "The Case Law of the Italian Constitutional Court between Network Theory and Philosophy of Information," in Proceedings of the Second International Workshop on Network Analysis in Law (NAIL 2014), 2014, pp. 26-38.

[9] R. Winkels, J. de Ruyter, and H. Kroese, "Determining Authority of Dutch Case Law." in Legal Knowledge and Information Systems (JU$R I X)$, ser. Frontiers in Artificial Intelligence and Applications, K. Atkinson, Ed., vol. 235. IOS Press, 2011, pp. 103-112.

[10] D. Bourcier and P. Mazzega, "Codification, law article and graphs," in Legal Knowledge and Information Systems (JURIX), ser. Frontiers in Artificial Intelligence and Applications, A. R. Lodder and L. Mommers, Eds., vol. 165. IOS Press, 2007, pp. 29-38.

[11] R. Boulet, P. Mazzega, and D. Bourcier, "A network approach to the french system of legal codes - part i: analysis of a dense network." Artificial Intelligence and Law, vol. 19, no. 4, pp. 333-355, 2011.

[12] M. Koniaris, I. Anagnostopoulos, and Y. Vassiliou, "Network Analysis in the Legal Domain: A complex model for European Union legal sources," CoRR, vol. abs/1501.0, 2015.

[13] F. Tarissan and R. Nollez-Goldbach, "Analysing the first case of the international criminal court from a network-science perspective," Journal of Complex Networks, pp. 1-19, 2016.

[14] J. M. Kleinberg, "Authoritative sources in a hyperlinked environment," Journal of the ACM, vol. 46, no. 5, pp. 604-632, 1999.

[15] F. Tarissan and R. Nollez-Goldbach, "Temporal properties of legal decision networks: A case study from the international criminal court," in Legal Knowledge and Information Systems (JURIX), 2015, pp. 111120.

[16] M. Derlen and J. Lindholm, "Goodbye van gend en loos, hello bosman? using network analysis to measure the importance of individual cjeu judgments," European Law Journal, vol. 20, no. 5, pp. 667-687, 2014.

[17] A. Mirshahvalad, J. Lindholm, M. Derlen, and M. Rosvall, "Significant communities in large sparse networks," PloS one, vol. 7, no. 3, p. e33721, 2012.

[18] S. Brin and L. Page, "Reprint of: The anatomy of a large-scale hypertextual web search engine," Computer networks, vol. 56, no. 18, pp. 3825-3833, 2012.

[19] Y. Lupu and E. Voeten, "Precedent in international courts: a network analysis of case citations by the european court of human rights," British Journal of Political Science, vol. 42, no. 02, pp. 413-439, 2012.

[20] K. J. Pelc, "The politics of precedent in international law: A social network application," American Political Science Review, vol. 108, no. 03, pp. 547-564, 2014.

[21] S. Puig, "Social capital in the arbitration market," European Journal of International Law, vol. 25, no. 2, pp. 387-424, 2014.

[22] U. Sadl and M. R. Madsen, "A "selfie" from luxembourg : The court of justice and the fabrication of the pre-accession case-law dossiers," Columbia Journal of European Law, vol. 22, no. 2, 2016.

[23] U. Sadl, "The role of effet utile in preserving the continuity and authority of european union law:: Evidence from the citation web of the preaccession case law of the court of justice of the eu," European Journal of Legal Studies, vol. 8, no. 1, pp. 18-45, 72015.

[24] M. Maduro and L. Azoulai, The past and future of EU law: the classics of EU law revisited on the 50th anniversary of the Rome Treaty. Bloomsbury Publishing, 2010.

[25] S. Dothan, Reputation and Judicial Tactics: A Theory of National and International Courts. Cambridge Univ Press, 2015. 